Western University

Scholarship@Western

Aboriginal Policy Research Consortium International (APRCi)

2007

\title{
Desistance and Identity Change among Aboriginal Females
}

John D. Hundleby

Barbara M. Gfellner

Darrell Racine

Follow this and additional works at: https://ir.lib.uwo.ca/aprci

Part of the Criminology Commons

Citation of this paper:

Hundleby, John D.; Gfellner, Barbara M.; and Racine, Darrell, "Desistance and Identity Change among Aboriginal Females" (2007). Aboriginal Policy Research Consortium International (APRCi). 291.

https://ir.lib.uwo.ca/aprci/291 
This article was downloaded by: [University of Western Ontario]

On: 09 December 2012, At: 07: 32

Publisher: Psychology Press

Informa Ltd Registered in England and Wales Registered Number: 1072954

Registered office: Mortimer House, 37-41 Mortimer Street, London W1T 3J H, UK

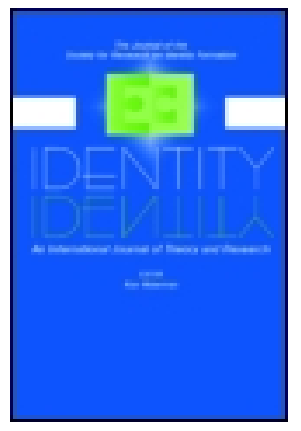

\section{Identity: An International J ournal of Theory and Research}

Publication details, including instructions for authors and subscription information:

http:// www. tandfonline.com/loi/ hidn20

\section{Desistance and Identity Change among Aboriginal Females}

J ohn D. Hundleby ${ }^{a}$, Barbara M. Gfellner ${ }^{b} \&$ Darrell Racine $^{b}$

a University of Guelph,

${ }^{\mathrm{b}}$ Brandon University,

Version of record first published: 05 Dec 2007.

To cite this article: J ohn D. Hundleby, Barbara M. Gfellner \& Darrell Racine (2007): Desistance and Identity Change among Aboriginal Females, Identity: An International J ournal of Theory and Research, 7:3, 225-253

To link to this article: http:// dx. doi.org/ 10.1080/ 15283480709336932

\section{PLEASE SCROLL DOWN FOR ARTICLE}

Full terms and conditions of use: http://www.tandfonline.com/page/termsand-conditions

This article may be used for research, teaching, and private study purposes. Any substantial or systematic reproduction, redistribution, reselling, loan, sub-licensing, systematic supply, or distribution in any form to anyone is expressly forbidden.

The publisher does not give any warranty express or implied or make any representation that the contents will be complete or accurate or up to date. The accuracy of any instructions, formulae, and drug doses should be independently verified with primary sources. The publisher shall not be liable for any loss, actions, claims, proceedings, demand, or costs or damages 
whatsoever or howsoever caused arising directly or indirectly in connection with or arising out of the use of this material. 


\title{
Desistance and Identity Change among Aboriginal Females
}

\author{
John D. Hundleby \\ University of Guelph \\ Barbara M. Gfellner and Darrell Racine \\ Brandon University
}

\begin{abstract}
This study concerns the factors that are involved in a change from antisocial and criminal behavior to the development of a prosocial sense of identity in ten Aboriginal females. Data were obtained from recorded semi-structured interviews that included questionnaires and open-ended questions. These women had dysfunctional backgrounds and lifestyles yet ceased such behavior and entered university life. Findings indicated the resilience of these women. They overcame extreme disadvantages and "turned around" to develop purposeful and adaptive lives. Gaining a sense of their cultural background and integrating aspects of Aboriginal heritage into their sense of self were interwoven themes in the process. Findings are considered in terms of desistence and identity change from a maladaptive lifestyle with implications for cultural socialization.
\end{abstract}

There is increasing interest in the role of culture and ethnicity in identity development and how these contribute to psychosocial functioning, with attention to the diversity of historical and contextual experiences, and how such circumstances may be incorporated in one's sense of self (Kundu \& Adams, 2005; Phinney, 1996; Phinney, 2005; Wijeyesinghe \& Jackson, 2001). Most studies focus on minority groups within mainstream societies. It is surprising that few researchers have considered the situation of Aboriginal people given their unique historical background. Our study concerned Aboriginal women who parted from a life of problem and antisocial behavior and adopted a positive view of themselves and their worlds - a change in identity.

Correspondence should be addressed to John D. Hundleby, University of Guelph, Guelph, Ontario, Canada N1X 1X6. E-mail: jhundleb@uoguelph.ca 
First Nations and Aboriginal ${ }^{1}$ people are the largest and most disadvantaged minority in Canada (Comeau \& Santin, 1995). They comprise approximately $14 \%$ of the population in the prairie provinces. Aboriginal children and adolescents are the fastest growing segment of young people in the country (Statistics Canada, 2003). Although the literature on Aboriginal people is expanding, much of it pertains to epidemiological reports that underscore a litany of social, physical, and mental health difficulties that severely compromise psychosocial functioning and well-being (Comeau \& Santin, 1995). Indeed, an awareness of the dynamics involved in Aboriginal identity and how it contributes to adaptive development is essential to aid future generations in achieving their potential.

In this study we assume that personal identity, defined broadly in terms of the self (e.g., Ashmore \& Jussim, 1997; Berzonsky, 1988; Byrne, 1996; Dweck, 2000; Erikson, 1968; Harter, 1999; Kroger, 2000; McAdam \& St. Aubin, 1985) provides a structure of attitudes, behaviors, and general lifestyle, giving purpose and direction to an individual's life. As such it is a concept that is inferred from self-reports and activities.

Desistance is a concept that is closer to a specific area of behavior. This could be very narrow, such as arson or wider in terms of the range of chargeable offenses under a legal code (Hughes, 1998; Maruna, 2001; Shover, 1996; Warr, 1998). In either case it is the cessation of specific behaviors, or range of behaviors, that is in question. This can be assessed by self-report on instances of behavior or by criminal records.

In addition to the cessation of criminal behavior, most studies on desistance report an increase in adaptive behavior. In this study of Aboriginal females, we used successful attendance at university as the outcome indicator of positive adjustment. The university environment — the people, study demands, and social life—is a marked contrast from that which Aboriginal women with a similar background to our sample have experienced. The contrast is such that much more than a simple cessation of criminal offenses is involved, though this is necessary. The "much more" involves a change in perception of self and others in a purposeful and prosocial way. This in turn implies a change in personal identity.

The objective of this study was to understand the course taken by Aboriginal women who attend university, particularly those with a behavioral background that would not make attendance very likely. We considered both desistance (the cessation of offenses) and the broader change in personal identity that can aid in desistance and also play a major role in the maintenance of such a change and the accompanying lifestyle. Our aim was to explore the factors, both positive and negative in this change and its maintenance.

\footnotetext{
${ }^{1}$ The 2001 Census definition of Aboriginal includes all persons of native ancestry in Canada: North American Indian, Metis, and Inuit. Statistics Canada (2003). 2001 Census: Analysis Series. Aboriginal people of Canada: A demographic profile. Ottawa. . First Nations and Aboriginal is the contemporary term for Aboriginal people in Canada.
} 


\section{BACKGROUND AND OVERVIEW}

\section{Cultural Context}

Desistance provides an appropriate backdrop from which to investigate Aboriginal identity development given the over-representation of Aboriginal people (including men, women, and youth) in the criminal justice system (Aboriginal Justice Implementation Commission (AJIC, 2001). In the past decade, a number of commissions, reports, and roundtables (AJIC, 2001; Royal Commission on Aboriginal Peoples, 1993; Royal Commission on Aboriginal Peoples, 1995) have described this disproportionate representation and advanced recommendations to ameliorate the situation. Such directives advocate culturally relevant approaches for dealing with transgressions. From this perspective Aboriginal restorative justice is centered on the process of cultural reintegration and identity development. This involves commencing a "healing journey" in which individuals are exposed to their cultural background through involvement in traditional and spiritual practices. For many, this experience occurs for the first time through government-funded projects in prison (AJIC, 2001). Several initiatives have focused on the community with emphasis on cultural learning as the means of addressing systemic difficulties (Royal Commission on Aboriginal Peoples, 1995). In this way traditional approaches and cultural socialization are the focus of intervention.

Traditional Aboriginal culture is grounded in a symbolism that relies on ceremony and stories as a system to view the world. This native world-view provides a spiritual infrastructure of Aboriginal life that gives meaning to events and what it means to be Aboriginal. It operates in a social setting characterized by collectivism. The emphasis is on balance and harmony of the individual in relation to: self, family, and community; the spiritual world; and the physical environment (Freeman, 1992; Horse, 2001; Lane, Bopp, \& Bopp, 1984; Ross, 1996).

Unfortunately, this traditional native framework has been lost to recent generations. In the past 200 years Aboriginal identity eroded in a legacy of cultural destruction due to colonialism, missionization, the repudiation and suppression of many customs and beliefs, the establishment of reservations, and residential (boarding) schools. This forced assimilation led to loss of language, traditions, and cultural socialization (Bull, 1991; Ing, 1991; Morrissette, 1994). Contemporary children and youth continue to be threatened and unable to protect the self from an unsympathetic school system (Hart, 2002). In this way, they are marginalized. They are not taught their own tradition in schools or at home, and what they are taught threatens an already fragile identity. Ubiquitous loss of self has been emphasized as a major source of difficulties among Aboriginal people (Deyhle, 1998; Dodd, Nelson, \& Hofland, 1994) and Aboriginal youth are considered the most disadvantaged minority in terms of identity development (Arnett, 2004). 
Evidence of cultural dissolution is seen in the extreme disadvantage of many Aboriginal people on reserves and in cities (Johnston, 1997; La Prairie, 2002). The chronic adversity of these environments includes a multitude of contextual and psychosocial problems that occur with substantially higher rates than for the non-Aboriginal population. Some of these involve: over-representation in the justice system; domestic violence and abuse; alcohol and drug misuse; teen pregnancy; prostitution; depression and suicide; chronic and infectious diseases; lower education completed; unemployment; lack of housing; and admission to foster care (AJIC, 2001; Centre for Aboriginal Health Research, 1998; Comeau \& Santin, 1995; Johnston, 1997; Manitoba Aboriginal People and Northern Affairs, 2000). Similarities between Native Americans in the United States, Sami in Norway, Maori in Australia, and Aboriginal people in Canada suggest that our findings may be relevant to indigenous peoples elsewhere.

\section{Desistance and Identity Change}

Desistance means change in some problematic behaviors, and more specifically, change in a particular area of problem behavior and lifestyle that has been sustained over a substantial period of time. Maruna (2001) defined desistance as "the long-term abstinence from crime among individuals who had previously engaged in persistent patterns of criminal offending" (p. 26). There is similarity with some of the resilience literature insofar as desisters are characterized in terms of chronic adversity or extreme vulnerability and lacking protective factors in their early environments (Hauser, 1999; Masten, Best \& Garmezy, 1990; Rutter, 1996; Werner \& Smith, 1992). However, unlike research in resilience, desisters are those who have been victims of their environments in terms of dire outcomes, and they subsequently "turn around." In comparison, those showing resilience have not necessarily engaged in problem behaviors. Retrospective analysis of personal narratives pertaining to desistance involves a description of the factors or process leading to this change. In this context, identity change refers to alteration in perceptions of the self and social world as discussed in the general domain of the self-concept and identity (including Eriksonian and other theories of self development). Miller and C'de Baca's (2001) conceptualization of quantum change refers to dramatic insightful turning points and mystical transformations or epiphanies that “... mark the beginning of lasting and often pervasive changes in a person's life. Both occur suddenly and ... usually involve a significant alteration in how one perceives other people, the world, oneself, and the relationships among them" (p. 21). In the literature on desistance, three themes in personal narratives of desisters have been contrasted with those of active offenders. These are: (a) an establishment of core beliefs that characterize the "true self"; (b) a sense of personal control; and (c) the desire to be productive and give something back to the next generation (Hughes, 1998; Maruna, 2001; Shover, 1996). 
Research on desistance is scanty, and this is particularly true for females rather than males, and even more so when the sample is Aboriginal rather than Caucasian. Research on this topic therefore has some similarity to sailing in uncharted waters. Other desistance studies involve, in the main, White and Black males or females with a background of persistent criminal offending (Baskin \& Robins, 1998, Hughes, 1998; Maruna, 2001; Shover, 1998; Sommers, Baskin \& Fagan, 1994). Three articles were located for Aboriginal individuals. At the Nechi Institute, an Aboriginal Centre for Alcohol Education (Nechi \& KAS Report, 1995), Aboriginal adults with a history of involvement in the justice system were asked to "tell their story." Findings indicated early turbulent years with alcohol leading to violence and crime. Aboriginal spirituality and culture were seen as a positive way of life. Watts and Gutierres (1997) examined substance dependency and recovery in a sample of Native Americans. McGowan and Nixon (2004) investigated problem gambling among Aboriginal men and women on a reserve. As with the Nechi report, the role of a culture was used to understand and address the respective behavior problems.

However, these studies on desistance included mostly males and did not consider sex differences. Other authors (Monture-Okanee, 1992; Nahanee, 1992; Tirado, 2005) have emphasized exacerbated difficulties for Aboriginal women associated with loss of status and respected position in Aboriginal society as well as racism and sexism that further compromise their integrity. Indeed, the experiences and issues relevant for Aboriginal women may be distinct from those of men on the path to desistance.

The evidence available suggests differences in factors related to desistance for Aboriginal persons in comparison to others. First, the socio-historical background of Aboriginal people has led to a pervasive context of chronic adversity for many, often punctuated by discrimination and lack of acceptance in mainstream society. This has been associated with marginality and difficulties in identity development. Second, native culture is grounded in collectivism with an emphasis on harmony of person, spirituality, and the environment. This ideology and value system has been contrasted with the individualistic orientation of the dominant society (O'Neill, 1996). However, many Aboriginal individuals are not acquainted with their heritage and culture due to pervasive losses in cultural socialization.

According to Erikson's theory (1968), psychosocial development proceeds in a series of stages associated with mastery of specific age-related strengths or virtues that are relevant across cultures and associated with identity development as an individual strives to achieve a sense of continuity with her past, present, and anticipated future. Marcia (1966) operationally defined identity development in terms of the presence of searching or questioning and commitment to a range of identity elements including a value ideology. Others (Berry, 1970; Berry \& Sam, 1996; Phinney, 1996; Phinney \& Rosenthal, 1997) have considered the process of enculturation that involves reconciling one's own ethnic identity with that of main- 
stream society. In comparison with other minorities, indigenous people are more likely to reflect marginal ethnic identity, that is alienation from their own as well as their majority culture (Berry, 1970; John, 1998). Although our study did not utilize the Eriksonian framework, this perspective provides an illustration of the complexities involved in identity development for Aboriginal people in general.

The present study was exploratory. Our objective was to identify some of the factors associated with desistance and identity change among Aboriginal females. We attempted to tackle the problem with a broad rather than a narrow focus. This was due to the dearth of directly relevant information and the unique nature of the sample and population from which it was drawn. As such we utilized a grounded theory approach (Glaser \& Strauss, 1967) to elucidate the major themes in women's narratives of desistance and change. At the same time several themes from the general desistance literature warranted attention. We expected to find similarity among Aboriginal women in perceptions of the self as associated with cessation of dysfunctional behavior including a sense of self-worth, personal control, and concern with the next generation.

\section{METHODS}

\section{Research Design}

The design was an in-depth case analysis. Although quantitative measures were used in conjunction with open-ended interviewing, quantitative analyses were not conducted due to the small sample size. Questionnaires and direct questions were used to obtain specific information. Respondents were encouraged to elaborate on the questions and "tell their stories."

\section{Participants}

The participants were 10 Aboriginal students at a medium-sized university in the prairie provinces of Canada. All were female with a mean age of 33.7 and a range of 22-40 years. Two students were divorced, three were married, one was in a common-law relationship, and four were single. All of the women had children, the mean number of children being 2.9 (1.9 male, 1.0 female). In terms of religion eight described themselves as Traditional Aboriginal, one was Protestant, and one was associated with Catholic, Protestant, and Traditional approaches. Family background during adolescence showed considerable variation with four living with biological parents, while six spent various times with adoptive, step, and foster parents as well as with biological parents. The mean number of siblings was 5.9 (2.5 brothers, 3.4 sisters) excluding early deaths and foster siblings. Three of the 
women spent most of their early years on a reserve, two were in a city, and five were in a small town.

\section{Procedure}

The selection of participants was non-random, based on either volunteering from direct contact with the interviewer (an Aboriginal instructor in the Native Studies Department) or from volunteering when made aware of the study. The interviews were carried out in a faculty member's office. The study met the University's approval for ethical standards of research with humans. Strict confidentiality was maintained. The interviews took between $1-1 / 2$ to 3 hours. At the start of the interview, but not previously, participants were informed that they would receive an honorarium of $\$ 25$ for taking part in the study. The interviews were recorded and subsequently transcribed. All data were coded and fictitious names used to protect the identity of participants. Transcripts were content analyzed by two raters for general themes using open coding as described by Strauss (1987) on blocks of text. This involved constant comparison of categorical themes until saturation was achieved. Individual protocols were then rated for the presence of the themes.

\section{Measures}

Both quantitative and qualitative methods were used including questionnaires and checklists as well as graphs and open-ended questions. The interview was extensive, covering the women's past and current life situation. This was necessary to establish the criteria for desistance and subsequent change. The structured and unstructured parts were arranged such that questionnaires and checklists were not clustered together. A copy of the complete instrument is available from the authors.

\section{Specific Oral Questions, Checklists, and Questionnaires}

Basic demographic information was obtained including age, martial status, sex and ages of children, and religious affiliation.

Using a Family Membership form and a Family History Chart, participants described chronologically (by year) the people in a woman's homes as she was growing up (e.g., biological father, foster mother) until the time of the interview. Information on location of residences (small town, reserve, city) was also obtained to provide an account of family membership and history. A series of issues were covered by direct oral questions that also gave the women full opportunity to give detailed accounts.

These were as follows. "Were your parents, brother(s) or sister(s) ever in trouble with the law or police?" If yes, "What happened? Who was involved?" 
"During your adolescence was there ever a problem in your family over drinking alcohol, in other words someone getting drunk or having too much to drink?" If yes, "Who was involved? How often?" "Were you ever the victim of physical or sexual abuse in your home?" If yes, "What happened? Who was involved? How often?" "How many of the friends that you had during the time between age 13 and the end of the period in which you were in trouble were involved in delinquent activities?" "What sort of trouble did they get into?" "Did they form a gang, semi-formal grouping, or numbered group?" "How many of the friends that you had during that time do you still see?" was rated on a six-point scale from "all of them" to "none of them."

"Who did you talk to when things were bothering you or when you needed help in any way?" "Would you say that your relationships with the other sex were satisfactory during the years between age 13 and the cessation of trouble?" "Why" or "Why not?" "Would you say that your present relationships with the other sex are satisfactory?" "Why" or "Why not?" "Since you were 13 have you had any serious injuries or illnesses?" If yes, "Do you mind telling what they were?"

"Did you attend high school?" "What were your experiences there?" "What year are you in at university? How are you doing? Do you like it?" "Have you given thought to an eventual career or are you uncertain?" "What are your long-term plans at the moment?" "How likely is it that you will reach your career goals?" "What would you like to do in terms of a career if you had the opportunity? What would be your ideal?" "What do you do in your leisure time?"

A 14-item checklist of frequency of problem behaviors up to the age of 13 with 7 categories, covering 0 to 19 or more occurrences, was completed by the respondents (e.g., ran away from home; broke into an apartment or home). Criminal offences from age 13 to the time of desistance were indexed by a behavior checklist of 25 items (ranging from murder to public order offenses) that provided the frequency of occurrences, charges, and convictions. The time span was from age 13 to the time of cessation of such acts.

A measure of alcohol and drug use at age 16 was a checklist of frequency for use of alcohol and 9 substances, including glue/solvents, marijuana, amphetamines/speed, barbiturates, LSD/acid, tranquillizers, crack/heroine, ecstasy, and other with 7 frequency categories from "not at all" to " 10 or more times". A similar checklist was used to index the frequency of substance use during the year prior to the interview. There were 7 frequency categories from "not at all" to "30 or more times". A separate question was used for tobacco use. "Do you use tobacco? When did you begin smoking? How many cigarettes do you use per day?"

The women's estimate of the ages when they regarded themselves as "free from trouble" (a personal estimate of the time of desistance) was when she "ceased to a considerable degree, the time you spent with your earlier friends, possibly moving from home, possibly moving from the area, and possibly may have announced to friends and family that you are changing the course of your life." 


\section{Lifeline Charting}

The women were told concerning their change "Let us assume that this was a change in thinking or attitude. By this I mean a change in your emotional attachment to another lifestyle. Note that this may not be the same as a change in behavior such as announcing to friends, family, and others that you are changing or leaving home or school. This emotional change concerns the extent to which you think about change, and think about change in a positive way. Was this emotional change rather sudden or was it taking place to some extent over some months or some years? Let us try to graph this."

Information on each person's progress in change was obtained through open discussion and the use of a lifeline graph focused on change on a 11 " $\times 14$ " sheet of paper. The graph gave attitude ${ }^{2}$ change plotted against chronological age. The levels on the vertical axis were: (0) Don't even think about change, change not considered as an option; (1) Aware of change as an option but see it for other people not for me; (2) Aware of change as an option and occasionally wonder what it would be like if one took the step; (3) Aware of change as an option and now quite frequently think about what it would be like if one took the step and what it would involve; and (4) Aware of change as an option, feel committed to it, and now do a lot of thinking about plans for the future and a career. Although spaced equally apart on the vertical axis, the levels were regarded as monotonically increasing. The horizontal axis gave age in years. The women then drew a line indicating their attitude level at each age. The interviewer did not intervene in any way while the line was being drawn, except on rare occasions to answer a question.

Upon completion of the graph the women were asked to place numbers on the graph line to indicate which of the following actions took place at that time: (1) Change school to get away from past; (2) Return to high school if dropped out; (3) Talk over changing one's lifestyle with a friend; (4) Talk over changing one's lifestyle with a parent(s); (5) Talk over changing one's lifestyle with a sympathetic counselor or adult (not parent); (6) Announce to your friends that you are changing; (7) Announce to your parents that you are changing; (8) Move out of the area or neighborhood; (9) Separate from earlier boyfriend or partner; (10) Stop going out with your earlier friends; (11) Purposely take on the care of a child; and (12) Other. These actions were listed on a page given to the women. The items provided a behavioral counterpart to the attitudinal change plotted on the graph. Any number of items could be used or repeated. The items were not regarded as a scale but as behaviors that might occur in the desistance process. Explanation and any additional comments by the women were also recorded.

\footnotetext{
${ }^{2}$ The word "attitude" is used in this article to present self-regard and regard for others and is broader in interpretation than is customary. Unfortunately, there does not seem to be a term that fits precisely the extent of personality change that we are considering.
} 
Two questionnaires followed completion of numbering on the graph. The first was Negative Aspects during the Process of Change that included a list of 14 persons or groups who were seen as potentially hindering the process of change (i.e., mother, father, brothers, sisters, friends, boyfriend, husband/common-law husband, other family, neighbors, police, high school teachers, person in corrections, social worker, employers, others). These were rated on a 5-point scale from "no negative effect all" to "had a very great negative effect." The second was Reasons for Change with 14 items including "mother, father, brother or sister, boyfriend, a judge, social worker or person in corrections, growing up, seeing what happens to people in prison, death of a relative or friend, being injured in an accident, an older person not mentioned above, a formal support group (e.g., Alcoholics Anonymous), grandparents, taking care of a child." The item sources were the desistance literature and discussions with Aboriginal women. Each item was rated on a 5-point scale from "did not help at all" to "extremely important in helping me."

\section{RESULTS}

Findings are presented initially for the quantitative components with elaboration as indicated in the respondents' recorded comments. The first two sections focus on contextual and behavioral factors used to establish the criteria of desistance and change. The subsequent sections present participants' perceptions of change and factors associated with it from the narrative accounts.

\section{Early Background/Contextual Factors}

As indicated earlier, some variability was reported in the family life of these women during their childhood and adolescence. Six spent various times with adoptive, step, and foster parents as well as with biological parents and four lived with biological parents. Three women spent their early years on a reserve, two were in a city, and five were in a small town. All had siblings and many had others (extended family, step siblings) in their home setting at various times.

\section{Parental/Sibling Criminal Behavior During Adolescence}

There was no report of either parent having trouble with the law as indexed by criminal convictions. Seven of the women indicated at least one sibling with one or more convictions, ranging from attempted murder to breaking and entering. Two of the remainder reported one or more siblings being involved in fighting and stealing (associated with use of alcohol), while one reported no delinquent activity among siblings. 


\section{Parental Use of Alcohol}

Nine of the women reported that during their childhood and early years their family had a major problem regarding alcohol. Drinking often occurred regularly on a binge basis, particularly over weekends.

\section{Sexual Abuse}

Eight of the women reported sexual abuse, often in childhood. The male offenders ranged from father, through brother to family friend.

\section{Past and Current Problem Behaviors}

\section{Problem Behavior Prior to and after Age 13}

All of the women were involved in activities falling within the problem behavior category suggested by Jessor and Jessor (1977), sometimes leading to police and court action, sometimes not. The behaviors were as follows (the numbers in parentheses being the number of women involved, not the number of occurrences which tends to be larger): shop-lifting (9); fighting (8); fighting a teacher (6); absent from school (7); destroyed property (6); running away (5); break and enter (4); sold marijuana (2); and carried knife or gun (1).

Nine were involved in delinquent and criminal behavior from age 13 to the age of desistance. The offenses over this period were more extensive and varied than for the earlier period, which would be expected. As in earlier problem behaviors, the numbers in parentheses indicate the number of women involved in each activity, regardless of frequency. The behaviors were as follows: theft (9); property damage (7); break and enter (7); assault (6); assault causing bodily harm (6); threatening (6); possession of stolen property (6); weapons' offenses (5); dangerous driving (5); breach of court order (4); drug possession (4); impaired driving (3); armed robbery (2); obstruction of justice (2); possession of open liquor (1); and fraud (1). Not all of these offenses led to convictions. The total number of convictions was 96, largely due to two women who had a combined total of 63 convictions, mainly for impaired driving and breach of court order.

\section{Drug and Alcohol Use}

Only two of the women were involved with drugs (excluding alcohol) at age 16 and had continued with some use to the time of the interview. Drug involvement consisted mainly of marijuana with very limited use of amphetamines, LSD, heroin, and ecstasy. At the same age use of alcohol presents a different picture, where a consistent pattern emerges. Heavy drinking took place over weekends (Friday to Sunday) for four of the women, while five drank "two to four times a week," and one drank "every day." A marked contrast is found in reportage of current alcohol 
use: six indicated zero use over the past year, three had minimal use (12 drinks or less over the year), while one drank "once a week". Cigarette smoking started at an average age of 9.5 years (range 5-16 years). One woman had never smoked. The mean number of cigarettes now smoked per day is 8.4 (range 4 to 25).

\section{Friends During Adolescence and Later}

The majority of friends were reported as being involved in trouble with the law. The only exception was a woman who had only "one or two" friends in trouble. The range of such problems included: drug and alcohol use; fighting; stealing cars; break and entering; drug trafficking; weapons offenses; property damage; and impaired driving. Four women said they had either been a member of a gang or had been on the fringes of a gang, four had been members of a cohesive group not classified as gang.

When asked about seeking help or support, five reported they turned to friends while four turned to no one. In answering the question concerning the number of friends at that time that they still see or have contact with, five said "none", three said "one or two", and one said "three or four".

\section{Education}

Nine women reported attending high school though typically this was for a short time. Only one did not attend at all. None of the women completed high school. Seven were suspended, mainly for fighting. Other reasons for suspension were: being disrespectful; non-attendance; drug use; swearing at teachers; and not doing homework.

In terms of current status at the university, three women were in first year, the others being second or third year. Commenting on the university, they all "liked it" or "liked it a lot". Of the small number who reported a grade point average (5), the mean grade was $\mathrm{C}$.

\section{Sexual Behavior}

In reply to a question concerning satisfaction with sexual behavior during adolescence, only two regarded this as "satisfactory," their replies being "yes, wasn't involved" and "yes, it was OK". Four negative answers and comments cited abusive relationships with the remaining comments being "No. Hated boys", "Was a Tom Boy", and "Always drunk or drinking". Present satisfaction was more positive with eight expressing satisfaction. The two remaining negative responses cited childhood experiences and a bad relationship with a White man as having an abiding effect. 


\section{Current Career Plans and Aspirations}

The majority indicated long-term plans for work in some form of social support capacity, specifically with an Aboriginal focus. Five women mentioned counseling. Others' plans included teaching, the law, and the police. Nine of the women regarded fulfillment of their plans as "likely" or "definite." The majority saw their ideal careers as being essentially the same as in their plans; the one exception was for "business" as the ideal.

\section{Leisure Activities}

All women spent time with their children. Other activities mentioned more than once were: exercising/weight-lifting (4); watching television or movies (3); traditional ceremonies (2); walking (2); and reading (2).

\section{Health}

Three women reported no health problems. Three reported abortions. Single references were made for broken knee, gall bladder operation, hepatitis B, kidney ailment, and being run over by a car.

\section{Desistance and Change}

The contextual circumstances and psychosocial and behavioral difficulties reported by the women in their early years were not atypical in terms of reports in the literature (Johnston, 1997). Nevertheless, these women showed exceptional resilience in overcoming their disadvantaged pasts. According to the criteria for desistance, the women appear to have "turned around" and developed adaptive lifestyles.

Women reported a conscious decision to change their lifestyle between 18 and 37 years of age, on an average, $8.9($ median $=8$ ) years earlier than their present age. This was consistent with each respondent's charting her pattern of change on the lifeline as seen in Figure 1.

In the Reasons for Change questionnaire the number of women endorsing "extremely important" in the list of possible influences was as follows: taking responsibility for a child (9); growing up, becoming more mature (7); mother (4); brother or sister (3); death of a relative or friend (3); an older person not included above (3); a formal support group, for example Alcoholics Anonymous (3); father (2); seeing what happens to people in prison (2); going steady with a boyfriend, husband or male partner (1); being injured in an accident (1); female friend or friends (0); a judge, social worker or person in corrections (0). One comment on endorsement of father and mother indicated that their behavior provided a negative incentive regarding change. 
Vera

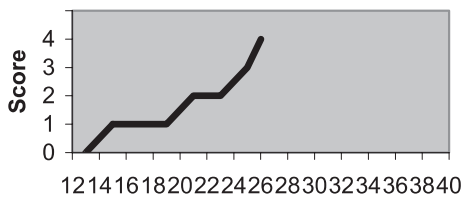

Age

Joan

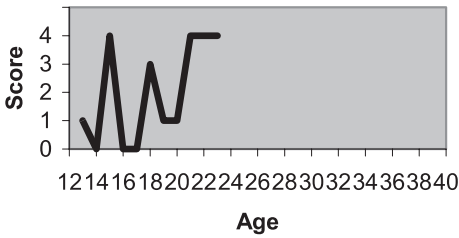

Mary

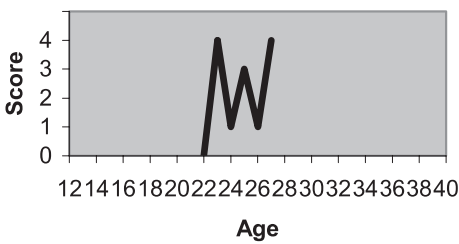

Iris

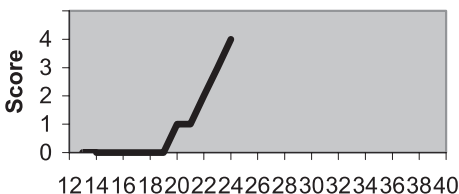

Age

June

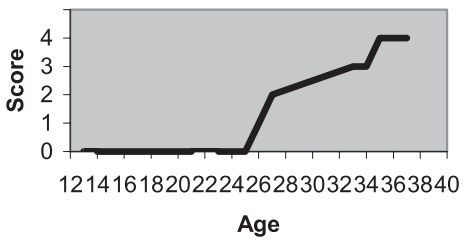

Edna

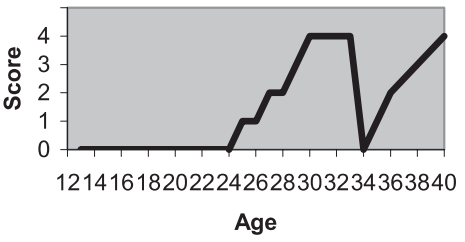

Cindy

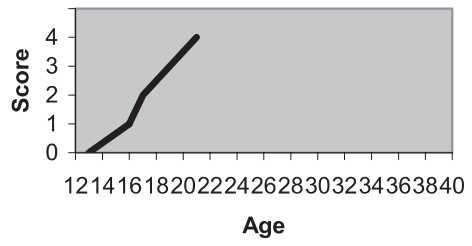

Nan

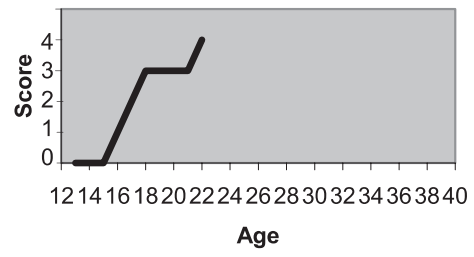

Jan

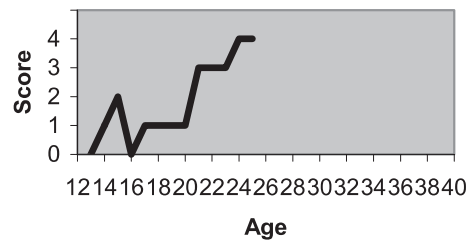

Sadie

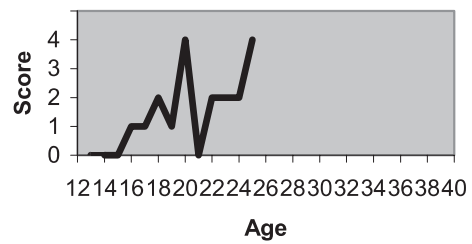

FIGURE 1 First Nations and Aboriginal females' charting of attitude change as a function of age. 
The frequency of endorsement of "substantial" or "very great" in the Negative Aspects During the Process of Change questionnaire were as follows: husband, common-law husband (4); father (4); boyfriend (4); mother (3); brothers (1); and others due to encouragement to use alcohol (1).

\section{The Pattern of Change}

Figure 1 shows the lifeline charting of the categories of change by age for each respondent. For five of the women the process of change seemed to be a steady climb over a series of years with no major breaks or accelerations (see Figure 1, June, Cindy, Iris, Nan, and Vera). The remaining five (Joan, Mary, Sadie, Edna, and Jan) showed irregularities that were viewed as major. Upward peaks were associated with domicile moving, abortions (forcing a woman to think more of the present and future for self and potential child), talking with a counselor and friends, and going back to high school. Downward troughs were associated with breaking up with a boyfriend and arriving at a foster home. Information from the unstructured part of the interview endorsed this. However in no case did we find a single major abrupt change in attitude or behavior that was maintained. This made the presence of a quantum change, as described by Miller and C'de Baca (2001) unclear.

\section{Themes from the Unstructured Part of the Interview}

Eight themes regarding the process of desistance and identity change emerged from the unstructured part of the interview. Some had extensive implications while others were narrower in their effect. These were categorized as: (1) factors contributing to earlier problems or predesistance; and (2) factors contributing to desistance and its maintenance. The first included: racism, discriminatory behaviors; and abuse, neglect, and the role of males. The second set of themes involved: recognition of the role of alcohol abuse; an emotionally disturbing event; self-concept and Aboriginal identity; care of children and generativity; role models and mentors; and maturity.

\section{Racism and Discriminatory Behaviors}

Many $(n=5)$ women reported experiencing racism in social situations (school, foster homes, community settings) both off the reserve and in their home communities. For example, Sadie had to attend school in the city because the reserve school burned down. She experienced "racism ... there but also racism in the community" because she was "viewed as a white person. So I didn't really have an identity." Similarly, Iris spoke of experiencing "prejudice from both white and native friends." For Edna there was ongoing harassment in terms of persistent visits 
from police; they would visit her at work to the point that she had difficulty holding a job. Mary indicated a similar situation.

\section{Abuse, Neglect, and the Role of Males}

Abuse and domestic violence were described as early and ongoing problems for seven of the women. This began within the family including extended family, neighbors, and foster placements and continued in later relationships with men. It is not surprising that, as indicated by Sadie, "I didn't talk about these problems... thought it was normal." These early experiences led to running away and relocation for some women during their early adolescent years, and subsequent involvement in abusive relationships with males. For Edna, "He (her husband) would come home from drinking and beat me up because he figured I was cheating on him. But I would be sitting at home ... this was out on the reserve and I couldn't get anyone to come and help me .... He told me that if I ever left him he would kill me and my little girl. So I was scared to leave .... I went to a women's shelter. He found me." (Interviewer: "How did you finally get him to stop?") "I wasn't scared of him any more. He thought I still was but I put my foot down and took him to court and charged him. And now he knows I'm not scared, so he doesn't really bother me." Several of the women indicated they were still dealing with the effects of past abuse in their lives.

Domestic violence and abuse occurs with greater frequency among Aboriginal women and children than other groups. It presents formidable challenges for women and communities (see AJIC, 2001: chapter 9; Monture-Okanee, 1992; Nahanee, 1992; Tirado, 2005).

The role of males in the early and adolescent years of the women's lives was generally regarded negatively. This was indicated in women's reports of negative influences on change as well as the narratives. For Cindy a more positive approach to males eventually emerged. "I have respect for myself, and I have respect for human beings, and I have respect for men .... I don't just think of men as sexual beings, I see them as people."

Women's narratives indicated neglect in their early years. This reflected contextual difficulties and lack of parenting skills among adults. Many of the women as children were left to fend for themselves with no guidance or direction. Some faced inappropriate expectations and demands. For Jan, "My mother ... never really wanted me to go to school ... when she couldn't find a sitter one of us ends up staying at home that day, so we couldn't go to school." (Interviewer: "Where was she going?") "Basically nowhere. She was always following my dad around .... I felt that that was supposed to be my lifestyle where I couldn't get to school." A similar account is from Nan concerning maternal influence. "She was just wanting always to run my life. That's the only way of life she knew and she thought drink- 
ing and fighting and all that was normal. When I started to stay away from them, stay away from her, she tried everything to pull me back."

The early home environments of these women were neither supportive nor did they teach children how to deal with prejudice in mainstream society. Women reported experiencing demeaning and disparaging treatment from family, spouses, and others when attempting to develop or engage in some positive behavior. This reflected negatively on self-image and created further obstacles for the women when they were trying to initiate some changes in lifestyle. Edna described her parents' response, "When I tried to change they would say you are too stupid to do it."

\section{Recognition of the Role of Alcohol Misuse}

It was generally agreed by the women that alcohol played an important role in their predesistance life. Abuse of alcohol appeared to permeate their families to the extent that such abuse could be regarded as the norm with attendant learning effects upon the women as children. Alcohol abuse also appeared to be closely involved in the carrying out of the delinquent behavior that then emerged and subsequently became focal in their lifestyle. It is also important to remember from the checklist data that alcohol misuse declined sharply at the time of desistance, with three women having attended Alcoholics Anonymous (AA).

For Joan there was a steady involvement with alcohol leading up to the break-up of her marriage and a custody battle over her children. This led to a suicide attempt followed by counseling and a change in attitude and behavior. "The counselor made me see things different ..." He said "What is the problem, can you pinpoint it?" I said "Yeah, my alcohol." Attendance at AA followed and this, and in turn, was followed by involvement in traditional activities, both being seen as playing major roles in change and its maintenance. It was suggested that AA dealt with the specific problem of alcohol while turning to traditional ways helped resolve the broad range of other problems that she faced and helped in avoiding a return to her previous lifestyle. It is not unreasonable to suppose that the cessation, or near cessation, of drinking had some landmark and symbolic implication in general—for there is little doubt that alcohol was regarded as a major cause of the problems in their lives.

Alcohol misuse has been considered a maladaptive coping style among Aboriginal people. It is related to many other health (and lifestyle) problems (e.g., May \& Moran, 1995).

\section{Emotionally Disturbing Event(s)}

A fourth theme was a deeply emotionally disturbing event. Such events regarded as bringing about change were: injury to self; death of a friend or relative; an unplanned pregnancy; having an abortion; being rescued by her family from a brutally controlling pimp; an auto accident in which her young child was injured 
(driver was intoxicated); landing in jail when she had responsibility for young children; and a spiritual experience in a sweat lodge. Such disturbing events could be regarded as benign or aversive. They either abruptly increased the desperation of the present situation, or abruptly offered an opportunity to leave the situation. Several women indicated an accumulation of such negative events until they decided to do something about their situation and they took the opportunity to initiate change in their lives. Such reports of "hitting rock bottom" are consistent with Miller and C'de Baca (2001).

\section{Self-Concept and Aboriginal Identity}

Perhaps the single most important theme concerned self-concept and a sense of purposefulness. The women felt that despite having a troubled past they now were in control of themselves and their future. Part of this was an evaluation of themselves at an earlier time. As Cindy remarked, "I had no respect for myself, or anybody else for that matter, so that got me into a lot of trouble .... And I had no trust at all of men or even boys .... I was really lonely, I was looking for love in all the wrong places" and later "... only that the fact, finally, who I was as an Aboriginal woman had the most effect on my healing journey."

A slightly different view was expressed by Jan "I changed direction basically because I took a look at myself and realized that I was nobody. Doing all the drinking and drugs and stuff, seeing everybody. I just kind of took a look at my other friends and starting realizing that, hey, they are moving on and I'm staying behind and I didn't want to be behind any more. So, I just figured I had to change." Later in the interview it became clear that her friends were going to college.

For Iris, the development of identity was complicated by her not admitting to native ancestry through her school years. "I grew up in a Ukrainian community, the first native family to live there. And I was asked when I was a kid "Are you Chinese, are you Philippino?" I would say yes, never telling anyone what I really was ... and I think that's why my parents used to ship me off to the reserve every summer ... kindergarten through high school I never like told anyone that I was an Indian, never. Because they wouldn't accept me for who I was." For Edna "I never went for counseling. I never followed AA. I just decided that was it. I didn't want it (that life) any more. I wanted to do something better for myself and my family." This sense of self worth and personal control is consistent with the desistance literature (Hughes, 1998; Maruna, 2001; Shover, 1996).

Prominent in the women's accounts of their sense of self was recognition of oneself as an Aboriginal person. In most cases this included some involvement in traditional activities, ceremonies, and learning about their cultural heritage. This realization appeared to provide a value structure that gave meaning and purpose to actions and beliefs, and gave awareness of one's roots and an alternative life course. Cindy described this most succinctly, "Finding out who I am through my 
native culture helped me a lot. Talking to elders, going to sweat lodges, smudging ... finding out who I was as an Aboriginal woman had the most effect on my healing journey and because accepting the fact that I am Aboriginal and accepting that I am different in a good way, I think had everything to do with healing and starting my healing journey."

For these women the path to healing (i.e., desistance and identity change) involved gaining an awareness of their heritage and traditional Aboriginal culture. This provided a framework for understanding their past and it offered directions for the present and future. Indeed, the extent to which one's cultural background is explored and integrated into the sense of self may be vitally important to the maintenance of change.

\section{Care of Children and Generativity}

Another important theme was having a child and the care of children. In several cases a presumably unplanned pregnancy and birth of a child brought a greatly increased sense of responsibility. This concern continued and is continuing. For Mary the necessity to move from a city to a less dangerous environment was due to gang involvement by her children. A similar theme of "respect and concern for children" was described by Hughes (1998) with a sample of 20 white male criminal desisters.

Many women reflected on their own childhood and expressed wanting more for their children. According to Jan, after her child was born she "... realized I didn't want to be on social assistance, didn't want to be like other people on the reserve." Again, the importance of culture was evident in concerns about children. In dealing with parenting, some women expressed a desire to raise their children in the traditional Aboriginal way. Often this involved consideration of their past experiences. According to Mary, "I saw my childhood all over again in (the behaviors of) my children." Similarly, for Joan it was “... important to look at the impact of (my) past on the life of (my) children." Her son was suicidal with identity problems and difficulties in how he sees himself and relationships. Sadie returned to her reserve to escape problems in the urban environment and found that her entire family had begun to heal themselves (traditional healing) and her sister led the way for her. She later said, "I would like to teach people more about our traditional values and beliefs and culture. That's missing from our native people. I find it more relevant because this is how I began my healing ... going the traditional way was a beautiful experience."

Such themes of care for children reflect generativity. Generativity is the emergent value of Erikson's seventh stage of psychosocial development that typically occurs during the middle years of adulthood subsequent to resolution of identity and intimacy issues. Broadly defined, it reflects a concern with the capacity to care for others, for future generations, and a giving back to society. Stewart, Fantz, and 
Layton (1988) indicated five generative themes: care of others; general desire to make a lasting contribution to society; concern's for one's children; need to be needed; and productivity/growth. McAdams and de St. Aubin (1998) elaborated the concept of generativity to include concerns, values, and behaviors. Generative themes were noted among male desisters in their desire to make some important contribution to their communities (Maruna, 2001) and to individuals who find themselves in trouble with the law (Shover, 1996).

Apart from a major life transition, generativity may be viewed as an important component of traditional Aboriginal culture with its focus on interdependence of person, family, and community (Horse, 2001; Lane, Bopp, \& Bopp, 1984; Ross, 1996). Further evidence of generativity is seen in the women's career plans and occupational goals. In each instance women are striving for positions that will enable them to assist and help their people.

\section{Role Models and Mentors}

There were few positive influences in the early lives of these women. However, some indication was given of role models who provided images of another life and thereby some vicarious if not tangible support. Joan said “... people connected with the church would take us to the gym on Friday nights ... being connected to people who lived different lives from the people I knew. They would invite us to their homes for a snack after. I think those people had a big impact on my life." And later at 15 or 16 years, she knew a young nun who seemed content with her lifestyle, "... she touched me deeply, I knew it was possible for me too. To be free of drugs and alcohol and all that kind of whole lifestyle and maybe have peace." In another case it was a male partner and in a third case a sister was mentioned as playing a substantial role in the change by providing direction in traditional healing. The presence of a role model, mentor, or support was noted in other accounts of desistance (Hughes, 1998; Maruna, 2001).

\section{Maturity}

Most women indicated a developmental aspect associated with change in terms of growing up, becoming more mature. Although less clear, this seemed to be associated with having children as well as discovering one's roots. This was not discussed specifically but some reference is given in women's accounts of their experiences at university.

\section{Transition to University}

Many Aboriginal students often are first exposed to their history and culture initially in Native Studies courses at university. This transformative experience may eventually have a role in facilitating change in terms of nurturing identity develop- 
ment. All the women were doing satisfactorily in their studies, with focused career plans and expectations of successful achievement. However, none of the women had completed high school and three had enrolled at university at previous times and subsequently dropped out. Regarding these occasions the women described themselves as "not ready" or "lacking in preparation." Sadie was sent to university by her father. She did not attend classes, became pregnant, had the baby, and became involved in an abusive relationship with the child's father. Alternatively, Vera and Cindy enrolled at university for the financial support available from their Band Council. In comparison, all women reported positive feelings about attending university now and had clear goals and direction. The pattern of dropping out and returning to university numerous times has been noted for Aboriginal students; they tend to require a longer period to complete programs and are older when they attend and graduate (Holmes, 2005). As well, fewer Aboriginal students attend university in comparison with technical and other post-secondary programs and the majority of Aboriginal students attending university are women (Manitoba Aboriginal and Northern Affairs, 2000).

Financial support for post-secondary schooling is available through Band Councils (Holmes, 2005); all of the women were receiving this assistance and would not have been able to attend university without this monetary support. In addition, most Aboriginal students would benefit from more holistic supportive resources to enable a successful transition and functioning at university (Malatest \& Associates, 2004; Silver, Klyne, \& Simard, 2003).

\section{Patterns of Identity Change}

For these women, the path to desistance and identity change was punctuated by exposure to their cultural heritage that was missing in their earlier years. This thread appears to be associated with other themes as they have special significance given the historical background of Aboriginal people. Although gaining cultural awareness was indicated in every case, the women showed some variability in the extent to which they had explored their culture and incorporated it into their "healing journey" and sense of self.

Ethnic identity models (Berry, 1970; Berry \& Sam, 1996; Phinney, 1996; Phinney \& Rosenthal, 1997) emphasize the complexities of integrating one's minority identity along with functioning adaptively in the majority culture. This includes the extent to which one identifies with both one's own culture and with mainstream society as separate dimensions. Using this conceptualization, the women seem to be operating more at the bicultural level (accepting both their own and mainstream values) rather than as assimilated (accepting mainstream values only), marginal (accepting neither their own nor mainstream values), or separated (accepting their own culture and rejecting mainstream values) in their identity development. 
According to Marcia (1966) exploration and commitment are the criteria for identity development. In terms of cultural identity, five women appeared to have been searching actively and attained some degree of commitment (although this can only be inferred as it was not discussed directly). Jan is in counseling, she indicated that "... traditional activities helped with healing .... I seek elders" advice." Mary returned to her reserve from the city, she said that "... being around aunties and extended family was good ... my older sister and relatives were sobering up, something had to change and it was me," at which point she became involved in traditional ways. Sadie reported similar circumstances with family and Cindy just emphasized traditional healing. She described her involvement in cultural ceremonies as important “... for my daughter. I want her to grow up in a traditional life. I want her to be proud of who she is and her culture ... and for me, my healing journey. They are like my AA meetings." Similar sentiments were expressed by Iris, she recounted the "... spiritual experience at sweats and (how) it changed me ...."

The other five women seemed to be in earlier stages of discovery and exploration with regard to their heritage. They indicated that they were beginning to explore cultural activities such as sweats, sharing circles, and traditional beliefs. According to Joan, “... (I) don't know a lot about traditional native religion ... just in these past few years (I've been getting into it). I pray about it, what applies to me. What can I use? What will make me the Indian God made me? ... In the past few years I've been really going back and looking at my roots and where I came from and what I can use in my life story today." Similar comments were given by Edna. Nan said she was "Presbyterian growing up ... now more involved in native spiritual belief," Vera has “... only been attending sweats so far," and June is still dealing with childhood issues, going to AA, and counseling.

The women may reflect an array of trajectories in the process of identity change. According to traditional Anishinabe teachings (Lane, Bopp, \& Bopp, 1984), life transitions include four distinct periods (childhood, youth, adulthood, and old age), each with specific developmental tasks. The developmental task of youth involves extensive searching and ceremony culminating in self-definition when the individual achieves adult status in the community. Markstrom and Iborra (2003) described the relevance of puberty rites for Aboriginal identity development among Navaho girls. This includes strong support from family and community as the girl commences her spiritual quest. Indeed, historical circumstances have interfered seriously with socialization for this cultural progression.

\section{DISCUSSION}

The value of narrative accounts has been emphasized by researchers. This method is critical in gaining an understanding of low frequency behaviors or persons that are obscured in survey research with large-scale group data (Hauser, 1999). The 
small number of women in this study is indicative of the difficulty in isolating relevant cases. A similar problem was noted by McGowan and Nixon (2004) in locating desistent problem gamblers on a Blackfoot reserve. While the present study is extensive in breadth, it cannot be regarded as providing definitive answers to a set of specific research questions. Instead it raises questions and issues that Aboriginal communities, society, and social science research need to address.

In this report we used interviews to examine the experiences Aboriginal women have had that they regarded as important in their progress through desistance and identity change-their paths to healing. As with the desistance paradigm, we established the parameters for change, and then asked participants to describe and discuss the situations and factors they felt were relevant for them in the process.

What stands out is the resilience of these women. They overcame the extreme disadvantage of their early years and subsequently, "turned around" or "beat the odds" to move on and develop healthy and adaptive lives. Recognition of the need to change and becoming acquainted with their culture appear to be key factors for Aboriginal women. A similar theme of the role of culture was reported in the few studies available that focused on Aboriginal desistance. Native Americans in an alcohol and drug treatment program recognized their abuse as incongruent with authentic spirituality (Watts and Gutierres, 1997). Blackfoot problem gamblers living on a reserve explained their recovery through re-discovery of traditional knowledge, embodied as increasing involvement in ceremony (McGowen and Nixon, 2004, p. 28). This cultural understanding of problematic gambling and its impact on functioning was emphasized by "telling one's story" in a search for meaning within the context of their cultural worldview. As in the Watt and Gutierres's (1997) study, dysfunctional behavior was seen as an inappropriate spiritual path. As well, the role of culture was emphasized in the Nechi Institute (1995) findings. Indeed, it appears that a cumulation of problems and difficulties may lead to the decision to change and once this occurs the cultural framework provides the means to integrate and maintain the change.

At the same time, consistencies were seen with themes reported in other studies of desistance. These were: self-esteem and a sense of control (Hughes, 1998; Maruna, 2001; Shover, 1996); the care and responsibility for children (Hughes, 1998) and generativity (Hughes, 1998; Maruna, 2001); and one or more emotionally disturbing events (Maruna, 2001; Miller and C'de Baca, 2001). These women's experiences were seen as desperate in nature (e.g., getting away, running away, depression, drug overdose, suicide attempts), reflective of anomie and the hopelessness and helplessness of their situations. Nevertheless, these circumstances often contributed to the change. Themes that described distressing experiences (drinking, abuse, racism) were part of this constellation and often were seen to necessitate taking charge. However, the women had little support in their early lives, and few positive role models were evident. 
In summary, the major themes for the Aboriginal women were as follows. All were fiercely committed to their children, spending as much time as possible with them. The women were motivated to provide a better life for their children and to improve the environmental conditions that contributed to their own adjustment difficulties. This was seen in their career plans and goals as well. Most women indicated a developmental aspect associated with change in terms of "growing up" and "becoming more mature." And each described herself as having gained awareness of her cultural background and to a greater or lesser extent was integrating aspects of her heritage including spiritual beliefs and cultural practices into her sense of self.

Indeed these themes illustrate relevant indicators of desistance and identity change. Unfortunately, other aspects of the process are less clear. Was the apparent change in the lifestyle of these women no more than an example of a general increase in social sophistication and "growing up," essentially a matter of age? That this is unlikely as a major factor is suggested by the fact that although epidemiological statistics are not available on desistance it seems likely that these women represent a small minority among those with similar backgrounds and earlier behavior patterns. The issue of "Why this person, why now?" remains. There is also the problem of obtaining a more precise definition of what is meant by "growing up."

The sense of independence and taking control, which surely is a critical part of the process and maintenance of desistance and identity change, raises important issues. To what extent did an enhanced level of this personality characteristic first appear during the desistance process? Do individual differences in independence determine the extent to which certain environmental events hasten or retard the process of change? What is the relation between the sense of independence and the growth of a sense of identity? How does this develop within the context of a specific culture? Issues such as these require further research. That the women are now much more aware of an integrated sense of self and their place in the world seems clear.

Our account of factors influencing the change process has been based on the views expressed by the women. It is easy to infer that a certain event by itself produced abrupt change, for example, seeing the health decline in another person due to drug abuse. There is another possible interpretation. It could be that the women's attitude was changing without their being specifically aware of the change, and the events seen as major instigators of change being cognitively convenient landmarks. This is not to say that such events do not have influence, sometimes with major impact, but it may account for why a particular event was regarded as effective at a particular time.

Our findings emphasize the role of culture as providing the structure and motivation for self-regulation in the Aboriginal women's identity change. However, more precise information is needed for an understanding of how this comes about, 
the extent to which cultural values and spirituality are integrated into personal identity, and how this self-structure may be used in various areas of decision-making. Indeed, ethnic identity has been considered the most important aspect of self-definition of minority individuals (Aries \& Moorhead, 1989; Phinney, 1996) and this seems especially true for Aboriginal individuals.

There is increasing interest in traditional approaches to wellness including participation in cultural activities among Aboriginal people (e.g., Centre for Aboriginal Health Research, 1998). Clearly, the importance of culture in the well-being of Aboriginal communities is being recognized. Chandler and Lalonde (1998) reported decreased youth suicide associated with the extent to which Aboriginal communities were involved in cultural practices and exercised control in their communities. The First Nation community of Hollow Water was able to increase community well-being by reducing repeated sexual offending using a cultural approach (Royal Commission on Aboriginal Peoples, 1995). Similar focus on traditionalism is being voiced for health directives in Aboriginal communities (Canadian Institute for Health Information, 2004; Mignone and O'Neil, 2005). As well, exposure to cultural content in reserve schools has been associated with school attendance, retention, increased performance, and completion through cultural socialization (Bell et al., 2004). Taken together, these findings underscore the importance of culture in identity development of Aboriginal people.

There are a number of limitations in this study. Given the small number and selective nature of our sample, it is unclear how the findings would generalize to indigenous women in different circumstances, in particular those who have different aspirations and do not pursue university education. The university environment and other venues may impact differently on women's evolving sense of self. Following research on desistance and changes in one's sense of self, we have inferred that the women experienced a change in identity. Our findings are based on narrative accounts. No standardized measure of identity or self-definition was used. This prevents direct comparison with other research. At the same time, the narrative approach has been considered more consistent with indigenous ways (including telling one's story) than the use of formalized structured methods (McGowan \& Nixon, 2004). As well, sex differences could not be examined directly without comparative data from Aboriginal men.

Our study focused on Aboriginal women at only one particular point in time. With respect to future research, prospective longitudinal follow up is necessary to investigate how they negotiate new challenges in the process of completing their education, pursuing career goals, and meeting the demands of everyday living. It needs to be determined how these contexts and experiences are incorporated into one's sense of self. Further research is required for an understanding of the ways in which specific aspects of Aboriginal culture (such as relevant cultural experiences, models, and mentors within the cultural milieu) are utilized and how they contribute to self-development. More information on enculturation is essential to deter- 
mine the women's ethnic identity (status) and how they reconcile living in two worlds (minority and dominant cultures). The present research was exploratory and it offers suggestions for further investigation of identity development among Aboriginal people.

\section{ACKNOWLEDGMENTS}

This study was supported by a grant from the Vice-President Academic and Research to John Hundleby while he was the Stanley Knowles Distinguished Visiting Professor at Brandon University. We gratefully acknowledge the women involved in this project.

\section{REFERENCES}

Aboriginal Justice Implementation Commission. (2001). Violence towards Aboriginal women and children (Ch. 9), Final Report. Retrieved June 10, 2003, from AJIC Web site: http://www.ajic.mb.ca/ reports/final_ch09.html

Aboriginal Justice Implementation Commission. (2001). Final Report. Retrieved June 10, 2003, from AJIC Web site: http://www.ajic.mb.ca/reports/final summary.html

Aires, E., \& Moorhead, K. (1989). The importance of ethnicity in the development of identity of Black adolescents. Psychological Reports, 65, 75-82.

Arnett, J. J. (2004). Adolescence and emerging adulthood: A cultural approach (2nd ed.). Upper Saddle River, NJ: Pearson/Prentice Hall.

Ashmore, R., \& Jussim, L. (Eds.). (1997). Self and identity: Fundamental issues. Oxford, England: Oxford University Press.

Baskin, D. R., \& Sommers, I. B. (1998). Casualties of community disorder: Women's careers in violent crime. Boulder, CO: Westview Press.

Bell, D., Anderson, K., Fortin, T., Ottmann, J., Rose, S., Simard, L., \& Spencer, K. (2004). Sharing our success: Ten case studies in Aboriginal schooling. Kelowna, BC: Society for the Advancement of Education.

Berry, J. W. (1970). Marginality, stress, and ethnic identification in an acculturated Aboriginal community. Journal of Cross-Cultural Psychology, 1, 239-252.

Berry, J. W., \& Sam, D. L. (1997). Acculturation and adaptation. In J. W. Berry, M. H. Segall, \& C. Kagitcibasi (Eds.), Handbook of cross-cultural psychology, Vol. 3 (pp. 291-326), Boston, MA: Allyn \& Bacon.

Berzonsky, M. D. (1988). Self-theorists, identity status, and social cognition. In D. K. Lapsley \& F. C. Power (Eds.), Self, ego, and identity: Integrative approaches (pp. 243-262). New York: Springer-Verlag.

Bull, L. (1991). Indian residential schooling: The native perspective. Canadian Journal of Native Education, 18 (Supplement), 1-64.

Byrne, B. (1996). Measuring self-concept across the life span: Issues and instrumentation. Washington, DC: American Psychological Association.

Canadian Institute for Health Information. (2004). Improving the health of Canadians. Summary Report. Retrieved July 12, 2004, from CIHI Web site: http://www.cihi.ca 
Centre for Aboriginal Health Research. (1998). Manitoba first nations regional health survey: Final report. Winnipeg, Manitoba: Author.

Chandler, M. J., \& Lalonde, C. (1998). Cultural continuity as a hedge against suicide in Canada's First Nations. Transcultural Psychology, 35, 191-219.

Comeau, P., \& Santin, A. (1995). The first Canadians: A profile of Canada's native people today. Toronto, ON: James Lorimer.

Deyhle, D. (1998). From break dancing to heavy metal: Navajo youth, resistance, and identity. Youth and Society, 30, 3-31.

Dodd, J. M., Nelson, J. R., \& Hofland, B. H. (1994). Minority identity and self-concept: The American Indian experience. In T. M. Brinthaupt \& R. P. Lipka (Eds.), Changing the self: Philosophies, techniques, and experiences (pp. 307-336). New York: State University of New York Press.

Dweck, C. S. (2000). Self theories: Their role in motivation, personality, and development. Philadelphia, PA: Psychology Press.

Erikson, E. J. (1968). Identity: Youth and crisis. New York: W. W. Norton \& Co.

Farrall, S. (2002). Rethinking what works with offenders: Probation, social context, and desistance from crime. Portland, OR: Willan.

Freeman, M. M. R. (1992). The nature and utility of traditional ecological knowledge. Northern Perspectives, 20, 9-10.

Glaser, B. G., \& Strauss, A. L. (1967). The discovery of grounded theory: Strategies for qualitative research. Chicago, IL: Aldine.

Hart, M. (2002). Seeking mino-primatisiwin: An Aboriginal approach to helping. Halifax, NS: Fernwood.

Harter, S. (1999). The construction of the self: A developmental perspective. New York: Guilford.

Hauser, S. T. (1999). Understanding resilient outcomes: Adolescent lives across time and generations. Journal of Research on Adolescence, 9, 1-24.

Holmes, D. (2005). Embracing the differences: Post-secondary education among Aboriginal students, students with children, and students with disabilities. Montreal, QC: The Canadian Millenium Scholarship Foundation.

Horse, P. (2001). Reflections on American Indian identity. In C. L. Wijeyesinghe \& B. W. Jackson III (Eds.), New perspectives on racial identity development: A theoretical and practical anthology (pp. 91-107). New York: New York University Press.

Hughes, M. (1998). Turning points in the lives of young inner-city men forgoing destructive criminal behaviors: A qualitative study. Social Work Research, 22, 3, 143-151.

Ing, N. R. (1991). The effects of residential schools on native child-rearing practices. Canadian Journal of Native Education, 18, 65-118.

Jessor, R. \& Jessor, S. L. (1977). Problem behavior and psychosocial development: A longitudinal study of youth. New York: Academic Press.

John, R. (1998). Native American families. In C. H. Mindel, R. W. Haberstein, \& R. Wright, Jr. (Eds.), Ethnic families in America: Patterns and variations (pp. 382-421). Upper Saddle River, NJ: Prentice-Hall.

Johnston, J. C. (1997). Aboriginal offender survey: Case files and interview sample. Ottawa, Canada: R-61, Correctional Service of Canada.

Kroger, J. (2000). Identity development: Adolescence through adulthood. Thousand Oaks, CA: Sage.

Kundu, S., \& Adams, G. R. (2005). Identity formation, individuality, and connectedness in east Indian and non-east Indian female Canadian emerging adults. Identity, 5, 247-260.

Lane, Jr., Bopp, J., \& Bopp, M. (1984). The sacred tree. Lethbridge, AB: Four Worlds Development Press.

LaPrairie, C. (2002). Aboriginal over-representation in the criminal justice system: A tale of nine cities. Candian Journal of Criminology, 2, 181-208. 
Malatest, R. A., \& Associates Ltd. (2004). Aboriginal peoples and post-secondary education: What educators have learned. Montreal, PQ: Canadian Millennium Scholarship Foundation.

Manitoba Aboriginal and Northern Affairs. (2000). Aboriginal people in Manitoba. Retrieved May 10, 2003, from http:/www.gov.mb.ca/ana/apm2000/4/c.html.

Marcia, J. (1966). Development and validation of ego-identity status. Journal of Personality and Social Psychology, 5, 551-558.

Markstrom, C. A., \& Iborra, A. (2003). Adolescent identity formation and rites of passage. Journal of Research on Adolescents, 13, 399-425.

Maruna, S. (2001). Making good: How ex-convicts reform and rebuild their lives. Washington, DC: American Psychological Association.

Masten, A., Best, K., \& Garmzey, N. (1990). Resilience and development: Contributions from the study of children who overcame adversity. Development and Psychopathology, 2, 425-444.

May, P. A., \& Moran, J. R. (1995). Prevention of alcohol misuse: A review of health promotion efforts among American Indians. American Journal of Health Promotion, 9, 288-299.

McAdams, D. P., \& de St. Aubin, E. (1998). Generativity and adult development: How and why we care for the next generation. Washington, DC: American Psychological Association.

McGowan, V. M., \& Nixon, G. (2004). Blackfoot traditional knowledge in resolution of problem gambling: Getting gambled and seeking wholeness. Canadian Journal of Native Studies, 24, 7-35.

Mignone, J., \& O'Neil, J. (2005). Social capital and youth suicide risk factors in First Nations communities. Canadian Journal of Public Health, 96, S51-S54.

Miller, W. R. \& C'de Baca, J. (2001). Quantum change: When epiphanies and sudden insights transform ordinary lives. New York: Guilford Press.

Monture-Okanee, P. A. (1992). Reclaiming justice: Aboriginal women and justice initiatives in the 1990's. In the Royal Commission on Aboriginal peoples. Aboriginal people and the justice system: Report on the national roundtable on Aboriginal justice (pp. 105-132). Ottawa, ON: Minister of Supply and Services Canada.

Morrissette, P. (1994). The holocaust of First Nations people: Residual effects on parenting and treatment implications. Contemporary Family Therapy, 16, 381-392.

Nahanee, T. (1992). Dancing with a gorilla: Aboriginal women, justice, and the charter. In the Royal Commission on Aboriginal Peoples. Aboriginal peoples and the justice system: Report on the national roundtable on Aboriginal justice issues (pp. 359-382). Ottawa, ON: Minister of Supply and Services Canada.

Nechi Institute and KAS Corporation Limited. (1995). Healing, spirit, and recovery: Factors associated with successful integration. Solicitor General Canada, APC 11 CA. Retrieved May 15, 2004, from Web site: http://www.sgc.gc.ca/Epub/AboCor/eAPC11CA.htm

O'Neill, T. D. (1996). Disciplined hearts: History, identity, and depression in an American Indian community. Berkeley: University of California Press.

Phinney, J. S. (1996). Understanding ethnic diversity: The role of ethnic identity. American Behavioral Scientist, 40, 143-152.

Phinney, J. S. (2005). Ethnic identity in late modern times: A response to Rattansi and Phoenix. Identity 5, 194-195.

Phinney, J. S., \& Rosenthal, D. A. (1997). Ethnic identity in adolescence: Process, context, and outcome. In G. R. Adams, T. Gulotta, \& R. Montemayor (Eds.), Adolescent identity formation (pp. 145-172). Newbury Park, CA: Sage.

Ross, R. (1996). Return to the teachings: Exploring Aboriginal justice. Toronto, ON: Penguin Books Canada.

Royal Commission on Aboriginal Peoples. (1993). Aboriginal peoples and the justice system: Report on the national roundtable on Aboriginal justice issues. Ottawa, ON: Minister of Supply and Services Canada. 
Royal Commission on Aboriginal Peoples. (1995). Bridging the cultural divide: A report on Aboriginal people and the criminal justice system. Ottawa, ON: Minister of Supply and Services Canada.

Rutter, M. (1996) Transitions and turning points in developmental psychology: As applied to the age-span between childhood and mid-adulthood. International Journal of Behavioral Development, 19, 603-626.

Shover, N. (1996). Great pretenders: Pursuits and careers of persistent thieves. Boulder, CO: Westview Press.

Silver, J., Klyne, D., \& Simard, F. (2003). Aboriginal learners in selected adult learning centers in Manitoba. Winnipeg, MB: Canadian Centre for Policy Alternatives.

Statistics Canada. (2003). 2001 Census: Analysis series. Aboriginal people of Canada: A demographic profile. Retrieved May 15, 2005, from Statistics Canada Web site: http://www.statcan.ca/english/ freepub/89-589-XIE/free.htm

Stewart, A. J., Fantz, C., \& Layton, L. (1988). The changing self: Using personal documents to study lives. Journal of Personality, 56, 41-74.

Strauss, A. (1987). Qualitative analysis for social scientists. Cambridge, UK: University of Cambridge Press.

Sommers, I., Baskin, D. R., \& Fagan, J. (1994). Getting out of the life: crime desistance by female street offenders. Deviant Behavior, 15, 125-149.

Tirado, M. (2005). Reclaiming their status. American Indian Report, 21,12, 10-13.

Warr, M. (1998). Life-course transitions and desistance from crime. Criminology 36, 183-216.

Watts, L. K. \& Gutierres, S. E. (1997). A Native American-based cultural model of substance dependency and recovery. Human Organization, 56, 9-18.

Werner, E. E., \& Smith, R. S. (1992). Overcoming the odds. New York: Cornell University Press.

Wijeyesinghe, C. L., \& Jackson III, B. W. (2001). New perspectives on racial identity development: A theoretical and practical anthology. New York: New York University Press. 